\title{
Beyond food swamps and food deserts: exploring urban Australian food retail environment typologies
}

\author{
Cindy Needham ${ }^{1, *}$ (D), Claudia Strugnell ${ }^{1}$, Steven Allender ${ }^{1}$ and Liliana Orellana ${ }^{2}$ \\ 'Deakin University, Global Obesity Centre, Institute for Health Transformation, Geelong 3220, Australia: ${ }^{2}$ Deakin \\ University, Biostatistics Unit, Faculty of Health, Geelong, Australia
}

Submitted 20 July 2021: Final revision received 21 December 2021: Accepted 5 January 2022: First published online 13 January 2022

\begin{abstract}
Objective: 'Food deserts' and 'food swamps' are food retail environment typologies associated with unhealthy diet and obesity. The current study aimed to identify more complex food retail environment typologies and examine temporal trends. Design: Measures of food retail environment accessibility and relative healthy food availability were defined for small areas (SA2s) of Melbourne, Australia, from a census of food outlets operating in 2008, 2012, 2014 and 2016. SA2s were classified into typologies using a two-stage approach: (1) SA2s were sorted into twenty clusters according to accessibility and availability and (2) clusters were grouped using evidence-based thresholds.

Setting: The current study was set in Melbourne, the capital city of the state of Victoria, Australia.

Subjects: Food retail environments in 301 small areas (Statistical Area 2) located in Melbourne in 2008, 2012, 2014 and 2016.

Results: Six typologies were identified based on access (low, moderate and high) and healthy food availability including one where zero food outlets were present. Over the study period, SA2s experienced an overall increase in accessibility and healthiness. Distribution of typologies varied by geographic location and arealevel socio-economic position.

Conclusion: Multiple typologies with contrasting access and healthiness measures exist within Melbourne and these continue to change over time, and the majority of SA2s were dominated by the presence of unhealthy relative to healthy outlets, with SA2s experiencing growth and disadvantage having the lowest access and to a greater proportion of unhealthy outlets.
\end{abstract}

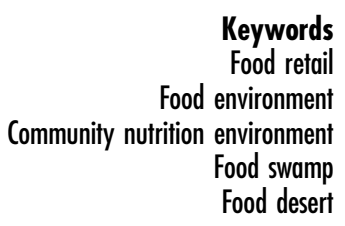

The prevalence of obesity continues to increase worldwide $^{(1,2)}$; and despite recommendations to address major drivers of the obesity epidemic such as the food system, interventions remain largely focused on individual lifestyle changes ${ }^{(3,4)}$. The effectiveness of interventions at the individual level is limited by the obesogenic nature of the food system which does not support communities to make healthy choices, e.g. individuals cannot overcome/overpower the entrenched environmental drivers $^{(3)}$. Analysis of data from member countries of the Organisation for Economic Co-operation and Development (OECD) indicates that it is increased supply and consequent consumption of calories that have contributed directly to the increased global prevalence of obesity $^{(5,6)}$. Per capita caloric supply is estimated by collecting data on food supply, calculating the quantity of foodstuffs produced and imported by a country and distinguishing between foods available for human consumption at the retail level and that for other uses (e.g. stock feed) $^{(7)}$.

The observed increase in caloric supply is at least in part driven by the changing distribution and accessibility of food resources (i.e. number, type and location of food outlets) in the 'food retail environment'(3). Food retail environments provide physical access to the food available to buy and play a key role in influencing food purchasing and subsequent dietary behaviours and prevalence of people with obesity ${ }^{(4)}$. Little is known about how the food retail environment is changing (i.e. quantity and healthiness of outlets) over time, the exception being a handful of studies set in the United Kingdom, North America and Australia which reported increasing numbers 
of food retail outlets ${ }^{(8)}$, which varied by type and density across geographic areas ${ }^{(9)}$ and by measures of socio-economic position ${ }^{(10-13)}$. For example, in the United Kingdom, one study identified an $80 \%$ growth in food outlets between 1980 and 2000, with the most dramatic growth observed for takeaways and restaurants ${ }^{(10)}$. A second study reported that the density per 10000 population (using data from the 2001 United Kingdom Census) of takeaway food outlets in Norfolk (United Kingdom) almost doubled between 1990 and 2008, supermarket density also increasing albeit by a smaller margin $(29 \%)^{(13)}$. In the current study, takeaway food outlet density increased at a more rapid rate in deprived areas, indicative of the non-uniform way in which food is retailed across and within communities ${ }^{(13)}$. Similarly, in a sample of neighbourhoods in the Bronx (New York) between 2008 and 2017, the growth in food retail establishments was twice that of the population growth $(5.7 \%)$ over the same period, with a significantly larger number of less healthy outlets opening in lower-income areas compared with high-income areas ${ }^{(12)}$. Over a shorter period of 10 months (2016-2017), using a sample of urban streets in the Bronx, modest growth in food retail outlets was observed, with a trend of increasing availability of less healthy compared with healthy food options from within food outlets ${ }^{(8)}$.

While there is growing evidence of the relationship between the food retail environment, dietary behaviours and obesity, strong evidence on the relationship is lacking and limits the development and implementation of healthy food retail environment policies ${ }^{(14)}$. Mixed results across studies are likely a consequence of heterogeneity in methods and measures, as ongoing debate exists as to what aspects of food retail environments are most influential on health ${ }^{(15-17)}$. A large portion of the literature seeks to examine disparities in food access and availability, to understand how this might be related to the disproportionate geographical distribution of people with obesity ${ }^{(15-17)}$. To do this, a common approach in the food retail environment literature is to examine absolute measures of access and availability for a single type of food outlet (i.e. density of supermarkets or fast-food outlets only) as a representation of the food retail environment. For example, the well-known term 'Food Desert' first used in the 1990s ${ }^{(18)}$ generally refers to areas with limited access to food retailers (supermarkets or grocery stores in most instances), where residents are restricted by physical and in some cases economic barriers to accessing healthy foods ${ }^{(19)}$. The term has successfully been used by the USA Federal Government to implement the 'Healthy Food Financing initiative' (HFFI). The HFFI provides funding to support the establishment of new supermarkets and grocery stores in areas identified as Food Deserts; in this instance defined as a low-income census tract within an urban area where at least $33 \%$ of the population cannot access a supermarket or large grocery store within one mile from home ${ }^{(20)}$.
The use of absolute measures involving only one food outlet type has, however, been critiqued due to its simplistic nature ${ }^{(15,21)}$. Results from earlier research suggest that studies encapsulating a broader range of food outlets are more likely to report associations in the expected direction (e.g. greater availability of healthy outlets associated to lower prevalence of people with overweight/obesity) ${ }^{(15)}$. Recent research suggests using relative measures of the food retail environment (i.e. the relative availability of healthy outlets from the sum of healthy and unhealthy food outlets), return more consistent findings in association with food purchasing and consumption behaviour (i.e. greater proportion of healthier outlets associated with healthier purchasing and lower prevalence of people with obesity) than those using only absolute measures ${ }^{(22,23)}$. Using relative measures, the term 'Food Swamp' has emerged to describe unhealthy food retail environments where the density of unhealthy food outlets (i.e. independent takeaways and global fast food chains) is much higher relative to healthy food outlets ${ }^{(24-26)}$. While encapsulating more food outlet types, relative measures of the food retail environment have also been critiqued due to inclusion of only outlets classified healthy or unhealthy, this simplistic classification leading to the exclusion of food outlets that are not clearly healthy or unhealthy; and as a result produce a simplified description of the complex and multidimensional food retail environment ${ }^{(23,27)}$. Excluding a large proportion of food outlets because they are difficult to categorise limits the ability to examine health effects, as it seems logical that less healthy and/or independent specialty stores may play an important role in health outcomes, an aspect missing in earlier studies ${ }^{(28,29)}$.

In an attempt to incorporate all food retail outlets, a recently developed tool by Moayyed et al. ${ }^{(30)}$ classifies all food retail outlets into twenty-four food outlet types and uses a Food Environment Score (FES) to categorise their healthiness on a scale from -10 to +10 , with zero included as a possible value in the scale. Using this tool, the healthiness of the food retail environment for a given area (i.e. suburb) is calculated by the sum of all food outlets FES, divided by the total number of outlets ${ }^{(30)}$. While inclusive, the FES provides only a measures of healthiness and does not provide a measure of accessibility (i.e. density of food outlets per population or area) which is an important aspect of consideration. Meyer et al. ${ }^{(23)}$ used Latent Class Analysis to longitudinally examine the neighbourhood food and physical activity environment using measures of accessibility (using $3 \mathrm{~km}$ buffers) around participant homes and their association with weight-related outcomes (diet quality, fast-food consumption, BMI and physical activity). This holistic approach identified six neighbourhood classes associated to some obesityrelated outcomes. The classes were not restricted by pre-existing classifications.

In the current study, we propose to use a census of the food outlets available in Greater Melbourne conducted at 
four different time points across eight years to identify trends in the food retail environment in an area experiencing rapid population and urban growth. The current study aimed to:

(1) Identify the most prominent food retail environment typologies in small geographical areas in Greater Melbourne, Victoria, based on a diverse set of measures of accessibility to all types of food outlets and relative availability of healthy food outlets.

(2) Describe how the prevalence of food retail environment typologies: (a) changed across the study period (2008-2016) and (b) varied according to distance from the Central Business District (CBD) or area-level socioeconomic position (SEP).

\section{Methods}

\section{Study region}

The current study is set in Greater Melbourne (hereinafter referred as to 'Melbourne') the capital city of the state of Victoria, Australia. Victoria is experiencing the fastest population growth in Australia ${ }^{(31)}$.

\section{Food retail environment data source and classification}

A retrospective census of food outlets was undertaken for 2008, 2012, 2014 and 2016; stores were classified by 'types' and 'healthiness' ${ }^{\text {(11) }}$. Retrospective food outlet data (name, type, address) for all food outlets located in Melbourne were extracted from hard copy business directories called the Yellow and White Pages, which publish government and commercial lists of businesses from information provided by telecommunications services ${ }^{(32)}$. Limited virtual ground truthing was performed in 2019 using Google and Google Street View to confirm current operation status and premise type ${ }^{(11)}$. Food outlets were classified into 17 types using an Australian food outlet classification tool (adapted to include an additional food outlet type 'salad bar/sushi bar') and allocated a FES representing outlet 'healthiness' using a 21-point scoring system ranging between -10 (least healthy) and +10 (most healthy) (see online supplementary material, Supplemental Table $1)^{(11,30)}$. Store types were collapsed into three groups according to their FES. Then, by type into seven groups of which we included only supermarkets in the current study, given they operate at a larger scale than most other retailers and serve a greater proportion of the Australian population ( $68 \%$ of food purchases were from supermarkets in 2019) ${ }^{(33)}$, warranting consideration independently as well as a contributor to healthier food retail availability (Table 1; see online supplementary material, Supplemental Table 1).
Table 1 Food retail environment: food outlet types and classifications

Food outlet types included within each accessibility measure*

1. Supermarkets: Minor \& Major supermarkets.

2. Healthy (Healthiness score range: +5 to +10 ): Supermarkets, Fruit and greengrocer, Butcher, Fish, Poultry shop, Salad/ Sandwich/Sushi bar.

3. Less Healthy (Healthiness score range: -4 to +4 ): Cafes and Restaurants (Independent and Franchise), Bakers, Delicatessen.

4. Unhealthy (Healthiness score range: -10 to -5 ): Fast-food, Takeaway independent, Pubs, General stores and Specialty extra.

5. Relative Healthy Food Availability: Healthy food outlets (Supermarkets and Greengrocers) Unhealthy food outlets (Fast-food and Takeaway independent).

Adapted from Needham et al. ${ }^{(11)}$

*Descirptions of each food outlt type are listed in Supplemental Table 1.

\section{Food retail environment: geographic scale}

Food outlet data were summarised at the Statistical Area 2 (SA2) level, which are medium-sized general purpose geographical zones (i.e. suburbs, residential districts) where communities interact together socially and economically ${ }^{(34,35)}$. With an average population of 10000 people, SA2s are the smallest area for which population Census data are released ${ }^{(34)}$. In 2016, there were 302 SA2s located entirely within the borders of Melbourne. The SA2 'Melbourne' (i.e. the CBD) was excluded due to the fact that food outlets in this area mainly service visitors ${ }^{(36)}$; therefore, 301 SA2's were included in the analysis. Food outlets were geocoded and then spatially joined to the 2016 SA2 boundaries Shapefile ${ }^{(34)}$ creating a data set that indicated, for the purpose of analysis, which SA2 each food outlet was located in.

\section{Food retail environment measures}

Food outlet data for each SA2 were used to create two dimensions of the food retail environment, 1) healthy food availability using the measure of Relative Healthy Food Availability (RHFA) and 2) accessibility using four measures referred to conjointly as the Food Retail Accessibility Measures (FRAMs) in the current study. Together, these measures indicate how much healthy food is available in a neighbourhood and how far on average people need to travel to access a range of different food outlet types within their neighbourhood.

\section{Relative Healtby Food Availability}

Relative healthy food availability is increasingly being used as a measure of food retail environment 'healthiness ${ }^{\prime(15)}$. In the current study, the RHFA represents the percentage of healthy food outlets available relative to the total number of food outlets (healthy plus unhealthy) within each SA2 boundary. To be consistent with previous literature and allow for comparability with former studies using more limited food outlet data, the RHFA only 
included supermarkets and greengrocers as healthy food outlets and only fast-food and independent takeaway for unhealthy food outlets ${ }^{(37)}$.

\section{Food retail accessibility measures}

Currently, there is no gold standard for measuring access to various types of food outlets. Building on previous work, ${ }^{(23,26)}$ we considered four measures of accessibility: density of 'supermarkets', 'healthy', 'less healthy' (i.e. neither clearly healthy nor unhealthy) and 'unhealthy' food outlets. Density of 'supermarkets' was included because the largest proportion of food is purchased at these retailers. Accessibility (density) within an SA2 was calculated as the number of outlets in each classification per $\mathrm{km}^{2}$. This measure indicates the average distance a person needs to travel within the SA2 to access one of these outlets, under the assumption that population and outlets are uniformly distributed across the SA2 $2^{(21,38)}$.

\section{Identification of Food Retail Environment Typologies}

A two-stage approach was followed to identify typologies: (1) SA2s were grouped into clusters using a K-means algorithm and (2) clusters were collapsed into typologies guided by the existing research evidence. Over the study period, some of the SA2s had no food outlets identified for some of the study years ( $n$ 29); therefore, 1175 'observations' (i.e. all SA2s with food outlets over the study period) were included in the cluster analysis described in Stage 1 .

\section{Stage 1. Unsupervised clustering}

The K-means algorithm with Euclidean (L2) distance was used to sort, based on measures of availability and accessibility, 1175 observations into $\mathrm{K}=20$ mutually exclusive groups $^{(39)}$. K = 20 was chosen to avoid collapsing large clusters, while retaining atypical clusters with few observations. Five measures of the food retail environment (RHFA and the four FRAMs; density of supermarkets, healthy, less healthy and unhealthy outlets per $\mathrm{km}^{2}$ ) were used as input variables. Variables were standardised using robust measures of location (median) and scale (median absolute deviation, MAD). Input variables were summarised by cluster. The cluster analysis was generated using SAS software version 9.4 .

\section{Stage 2. Evidence-based grouping of clusters in typologies}

With the aim of further collapsing similar clusters into a smaller number of typologies, meaningful thresholds for each of the five measures were derived from earlier studies that examined the effect of RHFA and accessibility measures on behaviours (i.e. food purchasing behaviour and diet) and health outcomes (i.e. obesity prevalence). Supplementary file 2 provides supporting information for thresholds.
Table 2 Thresholds used for the classification of each food retail environment measure

\begin{tabular}{lll}
\hline Measures & Categories & Classification \\
\hline $\begin{array}{c}\text { Relative Healthy Food } \\
\text { Availability (RHFA) }\end{array}$ & $\begin{array}{l}\text { Percentage of healthy } \\
\text { food resources } \\
\leq 25 \%\end{array}$ & RHFA \\
& $>25$ to $<50 \%$ & Low \\
& $\begin{array}{l}\text { Moderate } \\
\text { High }\end{array}$ \\
Food Retail Accessibility & Density per km2 & Access \\
Measures (FRAM) & & \\
Healthy, Less Healthy, & $<1$ & Low \\
Unhealthy & $\geq 1$ to $<2$ & Moderate \\
& $\geq 2$ & High \\
Supermarkets & $<0.625$ & Low \\
& 0.625 to $<1.25$ & Moderate \\
& $\geq 1.25$ & High \\
\hline
\end{tabular}

First, the cluster RHFA mean was classified into three levels (i.e. $\leq 25 \%,>25$ to $<50 \%, \geq 50 \%$ ). Then, each of the four FRAM means in a cluster was categorised in levels. For healthy, less healthy and unhealthy density we defined: 'Low' $(<1$ per km²), 'Moderate' $(\geq 1$ to $<2$ per km²) or 'High' $\left(\geq 2\right.$ per $\left.\mathrm{km}^{2}\right)$ as described in Table 2 . These FRAM categories reflect 'access' as a measure of distance only and do not reflect what would be considered 'good' access required for health. For supermarkets, given their larger size and scale of operation $^{(33)}$, we defined access as 'Low' $(<0.625$ per km²), 'Moderate' $\left(0.625\right.$ to $<1.25$ per $\left.\mathrm{km}^{2}\right)$ and 'High' $(\geq 1.25$ supermarkets per $\mathrm{km}^{2}$ ). The four dimensions of access were highly correlated; i.e. where the four access measures were low they were all very low (see online supplementary material, Supplemental Table 3, clusters 13 and 8); when one measures was moderate the other measures whilst low were higher in comparison (see online supplementary material, Supplemental Table 3, cluster 15); when one measure was high all others tended to be high or moderate. Therefore, the four access dimensions were summarised in one of three 'access' categories (low, moderate and high) based on the categorisation of the FRAMs: 'Low access' if all FRAMs were 'low'; 'Moderate access' where at least one (regardless of type) FRAM was 'Moderate' and 'High access' where at least one (regardless of type) FRAM was 'High'.

\section{Exploratory analysis of typologies by geographical location and socio-economic position}

Each SA2 was classified (based on the local government area (LGA) in which they were located) relative to distance from Melbourne's CBD as: 'Inner Ring' ( $<15 \mathrm{~km})$, 'Middle Ring' (15-25 km) and 'Outer Ring' (25-55 km) ${ }^{(11)}$. A fourth group included SA2s located in LGAs identified as Growth Areas (30-70 km from CBD; areas housing a large proportion of urban growth located on the urban fringe ${ }^{(40)}$.

The Australian Bureau of Statistics Socio-Economic Index for Areas, Index of Relative Socio-Economic Advantage and Disadvantage (SEIFA-IRSAD) at the SA2 level was used to define SEP quartiles, Q1 (lowest SEP) 
Table 3 Summary of food retail environment measures for each food retail environment typology by year

\begin{tabular}{|c|c|c|c|c|c|c|c|c|}
\hline \multirow[b]{2}{*}{ Year } & \multicolumn{2}{|c|}{2008} & \multicolumn{2}{|c|}{2012} & \multicolumn{2}{|c|}{2014} & \multicolumn{2}{|c|}{2016} \\
\hline & Mean & SD & Mean & SD & Mean & SD & Mean & SD \\
\hline \multicolumn{9}{|c|}{ Typology: Low access - High \% healthy } \\
\hline Number of SA2s (\%) & 23 & $7 \cdot 6$ & 22 & $7 \cdot 3$ & 19 & $6 \cdot 3$ & 17 & $5 \cdot 7$ \\
\hline RHFA \% & $64 \cdot 3$ & 17.5 & $65 \cdot 0$ & $17 \cdot 3$ & $68 \cdot 8$ & $19 \cdot 8$ & $66 \cdot 3$ & $19 \cdot 0$ \\
\hline Density Healthy per km² & 0.2 & 0.5 & 0.3 & 0.6 & 0.4 & 0.8 & 0.3 & 0.8 \\
\hline Density Less Healthy per km² & $0 . \overline{3}$ & 0.7 & 0.4 & 0.9 & 0.4 & 0.9 & 0.3 & 0.4 \\
\hline Density Unhealthy per $\mathrm{km}^{2}$ & 0.2 & 0.3 & 0.1 & 0.2 & 0.1 & 0.2 & 0.1 & 0.2 \\
\hline Density Supermarkets per km² & 0.1 & 0.2 & $0 \cdot 1$ & 0.2 & 0.1 & 0.2 & 0.1 & 0.9 \\
\hline \multicolumn{9}{|c|}{ Typology: Low access - Low \% healthy } \\
\hline Number of SA2s (\%) & 81 & $26 \cdot 9$ & 59 & $19 \cdot 6$ & 46 & $15 \cdot 3$ & 42 & 14 \\
\hline RHFA \% & $3 \cdot 1$ & 4.9 & $3 \cdot 0$ & $5 \cdot 2$ & 4.2 & $5 \cdot 6$ & 3.5 & $5 \cdot 1$ \\
\hline Density Healthy per km² & 0.1 & 0.2 & 0.1 & $0 . \overline{2}$ & $0 . \overline{2}$ & 0.2 & 0.2 & 0.2 \\
\hline Density Less Healthy per $\mathrm{km}^{2}$ & 0.6 & 0.6 & 0.5 & 0.6 & 0.7 & 0.7 & 0.7 & 0.7 \\
\hline Density Unhealthy per $\mathrm{km}^{2}$ & 1.0 & 0.9 & 0.8 & 0.8 & 0.9 & 0.8 & 0.9 & 0.9 \\
\hline Density Supermarkets per km² & 0.0 & 0.1 & 0.0 & 0.1 & 0.0 & 0.1 & 0.0 & $0 \cdot 1$ \\
\hline \multicolumn{9}{|c|}{ Typology: Moderate access - Low \% healthy } \\
\hline Number of SA2s (\%) & 85 & $28 \cdot 2$ & 99 & 32.9 & 101 & 33.6 & 99 & 32.9 \\
\hline RHFA \% & $22 \cdot 0$ & $6 . \overline{9}$ & $24 \cdot 3$ & $6 \cdot 8$ & 24.9 & $7 \cdot 3$ & $24 \cdot 0$ & $7 \cdot 6$ \\
\hline Density Healthy per km² & 0.5 & 0.3 & 0.5 & 0.3 & 0.5 & 0.3 & 0.4 & 0.3 \\
\hline Density Less Healthy per $\mathrm{km}^{2}$ & 0.9 & 0.7 & 0.9 & 0.6 & 0.8 & 0.6 & 0.9 & 0.7 \\
\hline Density Unhealthy per $\mathrm{km}^{2}$ & 1.2 & 0.7 & $1 \cdot 3$ & 0.8 & 1.2 & 0.9 & $1 \cdot 2$ & 0.8 \\
\hline Density Supermarkets per km² & 0.2 & 0.1 & 0.2 & 0.1 & 0.2 & 0.1 & 0.2 & 0.1 \\
\hline \multicolumn{9}{|c|}{ Typology: High Access - Low \% healthy } \\
\hline Number of SA2s & 39 & $13 \cdot 0$ & 45 & $15 \cdot 0$ & 43 & $14 \cdot 3$ & 49 & $16 \cdot 3$ \\
\hline RHFA \% & $18 \cdot 1$ & 9.9 & $19 \cdot 3$ & 7.8 & $19 \cdot 0$ & $8 \cdot 1$ & 18.9 & $8 \cdot 1$ \\
\hline Density Healthy per km² & 1.9 & 1.3 & $2 \cdot 1$ & 1.8 & 2.4 & 1.9 & 2.5 & $2 \cdot 3$ \\
\hline Density Less Healthy per $\mathrm{km}^{2}$ & 10.5 & $12 \cdot 1$ & $11 \cdot 6$ & $14 \cdot 8$ & 11.2 & 13.6 & 11.9 & $14 \cdot 8$ \\
\hline Density Unhealthy per $\mathrm{km}^{2}$ & $5 \cdot 7$ & $4 \cdot 1$ & $6 \cdot 1$ & 5.5 & 6.5 & $5 \cdot 7$ & $6 \cdot 7$ & 5.9 \\
\hline Density Supermarkets per km² & 0.5 & 0.5 & 0.7 & 0.7 & 0.7 & 0.5 & 0.7 & 0.6 \\
\hline \multicolumn{9}{|c|}{ Typology: High access - Moderate $\%$ healthy } \\
\hline Number of SA2s & 59 & $19 \cdot 6$ & 69 & $22 \cdot 9$ & 88 & $29 \cdot 2$ & 90 & 29.9 \\
\hline RHFA \% & $32 \cdot 0$ & $10 \cdot 6$ & $32 \cdot 5$ & $8 \cdot 1$ & $30 \cdot 9$ & $8 \cdot 1$ & 31.5 & $9 \cdot 6$ \\
\hline Density Healthy per km² & $2 \cdot 3$ & 1.6 & $2 \cdot 4$ & 1.8 & 2.6 & 1.9 & 2.4 & 1.5 \\
\hline Density Less Healthy per $\mathrm{km}^{2}$ & $7 \cdot 4$ & 10.7 & 5.5 & 5.4 & $6 \cdot 2$ & $9 \cdot 0$ & 5.9 & 8.2 \\
\hline Density Unhealthy per $\mathrm{km}^{2}$ & 3.8 & 3.5 & 3.9 & 2.6 & 4.1 & $3 \cdot 1$ & $4 \cdot 1$ & $3 \cdot 1$ \\
\hline Density Supermarkets per km² & 0.8 & 0.4 & 1.0 & 0.5 & 1.0 & 0.5 & 1.0 & 0.6 \\
\hline \multicolumn{9}{|l|}{ Typology: Zero Food Retail* ${ }^{\star}$} \\
\hline Number of SA2s & 22 & 4.7 & 15 & $2 \cdot 3$ & 12 & $1 \cdot 3$ & 12 & $1 \cdot 3$ \\
\hline
\end{tabular}

${ }^{*}$ Represents Statistical Area 2's with zero food retail outlets.

RHFA \%: percentage of healthy food outlets relative to healthy and unhealthy food retail outlets within each SA2.

SA2: Statistical Area 2: medium-sized general purpose areas representing geographical areas where community interact together socially and economically ${ }^{(34)}$.

to Q4 (highest SEP). SEIFA-IRSAD incorporates 25 collected measures of SEP (i.e. income, occupation, education, internet connection) which are used to summarise the relative disadvantage of the population within an area $^{(41-43)}$. Food retail environment data for years 2008 and 2012 were matched to the SEIFA-IRSAD quartiles from the 2011 census $^{(41)}$ and 2014 and 2016 food retail environment data to the 2016 census $^{(42)}$. Four SA2s had missing SEIFA-IRSAD due to the low population or low response rate for that census year ${ }^{(43)}$.

We report prevalence of typologies for each time point to explore trends over the study period by geographic location or area-level SEP.

\section{Results}

Six food retail environment typologies were identified for Melbourne SA2s, five using the two-stage procedure and a last typology corresponding to zero food outlets (Table 3).

Typology 1. Low access - High \% bealthy: comprised a single cluster of 81 'observations' (SA2s across years) with low food retail accessibility measures and the highest percentage of healthy food outlets. Typology 2. Low access Low \% healthy: comprised a single cluster of 228 observations (SA2s across years) with low food retail accessibility measures and the lowest percentage of healthy food outlets. Typology 3. Moderate access - Low \% healthy: comprised one single cluster comprising 384 observations with moderate accessibility to unhealthy outlets and low accessibility to supermarkets, healthy and less healthy outlets; and a low percentage of healthy outlets. Typology 4. High Access Low \% bealthy: comprised 10 clusters with a total of 176 observations (SA2s across years) with high access to all outlet types except supermarkets which was moderate in some of the clusters and a low percentage of healthy food outlets. Typology 5. High Access - Moderate \% healthy: comprised 
seven clusters which together contained 306 observations (SA2s across years) with high access to all outlets excluding supermarkets for which there was moderate access on average across the clusters and a moderate percentage of healthy outlets. Typology 6. Zero Food Retail: included 29 observations (SA2s across years) that had zero food retail outlets.

Over the study period (2008-2016), the food retail environment experienced an increase in RHFA and accessibility to food retail (Table 3). In 2008, the two most dominant typologies were Low access - Low \% bealthy and Moderate access - Low \% bealthy, together accounting for $55.1 \%$ of SA2s. In 2016, Moderate access - Low \% healthy and High Access - Moderate \% healthy typologies accounted for $62.8 \%$ of all SA2s. Over time, the proportion of Zero Food Retail, Low access - Low \% healthy and Low access - High \% bealthy SA2s slightly decreased by 3.4\%, 12.9\% and 1.9\%, respectively. In contrast, an increase of $4.7 \%$ was observed for Moderate access - Low \% healthy and 3.3\% for High access - Low \% bealthy, with the largest increase (10.3\%) observed in High Access - Moderate \% healthy.

\section{Distribution of food retail environment typologies across geographical location and time}

Table 4 presents the distribution of food retail environment typologies within years (rows) and within LGA-Ring (columns). The prevalence of typologies representing High access decreased when moving away from the CBD (Table 4, rows). This pattern was seen in all four years, although there was a small increase in the proportion of Moderate access - Low \% bealthy typologies in the Growth Area LGA-Ring over the study period (18.8\% to $33.3 \%$ ). The Inner and Middle Ring had the highest proportion of SA2s classified as High Access - Moderate \% bealthy $(27.1 \%$ and $57.6 \%)$ in 2008 , slightly decreasing over time (Table 4 , columns). Of all typologies, the proportion of High Access - Low \% bealthy was highest in the Inner Ring in 2008 (51.3\%), decreasing over time with the Middle Ring having the highest proportion (44.9\%) in 2016. In 2008, close to half (48.1\%) of the SA2s in the Growth Ring were classified as Low access - Low \% bealthy and two-thirds (64.3\%) were classified as Zero food retail. Over time the proportion of Moderate access - Low \% bealthy SA2s in the Growth Area Ring increased (18.8\% to $33.3 \%$ ). Over the study period, the prevalence of SA2s classified as Zero food retail decreased across all LGARings except for the Outer Ring where it remained relatively stable. The Middle Ring experienced an increase in the proportion of High access - Low\% Healthy (35.9\% to 44.9\%) and a decrease in Moderate access - Low \% bealthy (44.7\% to 33.3\%) and High Access - Moderate \% Healthy ( $57.6 \%$ to $47 \cdot 8 \%$ ) typologies. Supplemental File 4 presents maps of 'typologies' across Melbourne over time by LGA Ring.

\section{Food retail environment typology over time by area-level socio-economic position: Descriptive analysis}

Figure 1 and Supplemental File 4 present the distribution of 'typologies' within SEP (SEIFA-IRSAD) quartiles across Melbourne over time. It should be noted that Melbourne had an over-representation of the second highest (Q3) and highest (Q4) SEP quartiles. SA2 typologies representing RHFA and accessibility were not evenly distributed across SEIFA-IRSAD quartiles. There was a greater prevalence of High access typologies in areas of high SEP (Q4) compared to low SEP (Q1). Over time there was an increase in overall accessibility and RHFA across all SEP quartiles (Fig. 1). Supplementary Table 5 presents the distribution of typologies across SEP quartiles within each year (across rows). High SEP SA2s (Q4) housed over half $(56 \cdot 4 \%, n$ 22) of all High access - Low \% bealthy SA2s, this amount slightly increased over time. The highest SEP (Q4) SA2s maintained the largest portion of High access - Moderate \% healthy ( $45.8 \%, n 27$ in 2008; $42.7 \%, n 38$ in 2016) across the study period. The proportion of Low access - High \% healthy was highest in high SEP SA2s (Q4), remaining constant over time (range $40.9 \%, n 9$ in 2008; $50 \%, n 8$ in 2016). In 2008 Low access - Low \% bealthy typologies was highest in the second highest SEP SA2s (Q3: 34.6\%, n 27) this trend remaining over time. The second lowest SEP SA2s remained relatively stable in the mix of typologies over time, made up by predominantly Low and Moderate access typologies.

\section{Discussion}

We identified six distinct food retail environment typologies across the 301 SA2s in Melbourne between 2008 and 2016. All but one had low RHFA (i.e. low availability of healthy food stores relative to the sum of healthy and unhealthy outlets), and all had greater accessibility to unhealthy and less healthy food outlets, when compared with healthy food outlets and supermarkets. Three of the possible combinations of accessibility and availability were not identified in Melbourne: Moderate access Moderate \% bealthy, Moderate access - High \% bealthy and High access - High \% bealthy.

The majority of typologies were considered Low \% bealthy, with the average proportion of healthy food outlets available ranging from as low as $3.1 \%$ in SA2's classified as Low access - Low \% healthy to $24.9 \%$ in Moderate access Low \% healthy SA2s. Considered alongside the estimated population density of each SA2, this reflects approximately two-thirds of Melbourne residents (70\% in 2008; 62\% in 2016) living in SA2s where the food retail environment includes a large majority of unhealthy food outlets. An increase in access to food outlets was observed across Melbourne over time, with prevalence of Moderate and High access typologies increasing and Low access and Zero decreasing. 


\section{Public Health Nutrition}

Table 4 Food retail environment typology prevalence across years and geographic distance from CBD, in Greater Melbourne

\begin{tabular}{|c|c|c|c|c|c|c|c|c|c|c|c|c|c|c|}
\hline \multirow[b]{3}{*}{$\begin{array}{l}\text { Food Retail Environment } \\
\text { Typology }\end{array}$} & \multirow{2}{*}{\multicolumn{2}{|c|}{ INNER }} & \multirow[b]{3}{*}{$\begin{array}{c}\% \text { within } \\
\text { year }\end{array}$} & & & & \multicolumn{2}{|c|}{ LGA-Ring } & \multirow[b]{3}{*}{$\begin{array}{l}\% \text { within } \\
\text { year }\end{array}$} & & & \multirow[b]{3}{*}{$\begin{array}{c}\% \text { within } \\
\text { year }\end{array}$} & \multirow[b]{3}{*}{$\begin{array}{l}\text { Total } \\
\text { SA2s }\end{array}$} & \multirow[b]{3}{*}{$\begin{array}{l}\% \text { of } \\
\text { total }\end{array}$} \\
\hline & & & & \multicolumn{2}{|c|}{ MIDDLE } & \multirow[b]{2}{*}{$\begin{array}{l}\% \text { within } \\
\text { year }\end{array}$} & \multicolumn{2}{|c|}{ OUTER } & & \multicolumn{2}{|c|}{ GROWTH } & & & \\
\hline & $\begin{array}{l}\text { No. } \\
\text { SA2s }\end{array}$ & $\begin{array}{l}\% \text { within } \\
\text { Inner }\end{array}$ & & $\begin{array}{l}\text { No. } \\
\text { SA2s }\end{array}$ & $\begin{array}{l}\% \text { of within } \\
\text { Middle }\end{array}$ & & $\begin{array}{l}\text { No. } \\
\text { SA2s }\end{array}$ & $\begin{array}{l}\text { \% within } \\
\text { Outer }\end{array}$ & & $\begin{array}{l}\text { No. } \\
\text { SA2s }\end{array}$ & $\begin{array}{l}\% \text { within } \\
\text { Growth }\end{array}$ & & & \\
\hline \multicolumn{15}{|l|}{ Year: 2008} \\
\hline Zero food retail & 1 & $2 \cdot 2$ & $7 \cdot 1$ & 1 & 0.9 & $7 \cdot 1$ & 3 & 4.3 & 21.4 & 9 & $11 \cdot 8$ & $64 \cdot 3$ & 14 & 4.6 \\
\hline $\begin{array}{l}\text { Low access - High \% } \\
\text { healthy }\end{array}$ & 2 & 4.4 & 8.7 & 3 & $2 \cdot 8$ & $13 \cdot 0$ & 10 & $14 \cdot 1$ & $43 \cdot 5$ & 8 & $10 \cdot 5$ & $34 \cdot 8$ & 23 & $7 \cdot 6$ \\
\hline $\begin{array}{l}\text { Low access - Low \% } \\
\text { healthy }\end{array}$ & 3 & $6 \cdot 7$ & $3 \cdot 7$ & 19 & $17 \cdot 4$ & 23.5 & 20 & $28 \cdot 2$ & $24 \cdot 7$ & 39 & $51 \cdot 3$ & $48 \cdot 1$ & 81 & 26.9 \\
\hline $\begin{array}{l}\text { Moderate access - Low \% } \\
\text { healthy }\end{array}$ & 3 & $6 \cdot 7$ & 3.5 & 38 & 34.9 & $44 \cdot 7$ & 28 & 39.4 & $32 \cdot 9$ & 16 & $21 \cdot 1$ & $18 \cdot 8$ & 85 & $28 \cdot 2$ \\
\hline $\begin{array}{l}\text { High access - Low \% } \\
\text { healthy }\end{array}$ & 20 & 44.4 & $51 \cdot 3$ & 14 & $12 \cdot 8$ & 35.9 & 3 & $4 \cdot 2$ & $7 \cdot 7$ & 2 & $2 \cdot 6$ & $5 \cdot 1$ & 39 & $13 \cdot 0$ \\
\hline \multirow{2}{*}{$\begin{array}{l}\text { High access - Moderate \% } \\
\text { healthy }\end{array}$} & 16 & $35 \cdot 6$ & $27 \cdot 1$ & 34 & $31 \cdot 2$ & $57 \cdot 6$ & 7 & 9.9 & $11 \cdot 9$ & 2 & $2 \cdot 6$ & 3.4 & 59 & $19 \cdot 6$ \\
\hline & \multicolumn{3}{|c|}{ Year: 2012} & 109 & $100 \cdot 0$ & $36 \cdot 2$ & 71 & $100 \cdot 0$ & 23.6 & 76 & $100 \cdot 0$ & $25 \cdot 2$ & & $100 \cdot 0$ \\
\hline Zero food retail & 0 & 0.0 & 0.00 & 0 & 0.0 & 0.0 & 3 & $4 \cdot 2$ & $42 \cdot 9$ & 4 & $5 \cdot 3$ & $57 \cdot 1$ & 7 & $2 \cdot 3$ \\
\hline $\begin{array}{l}\text { Low access - High \% } \\
\text { healthy }\end{array}$ & 2 & 4.4 & $9 \cdot 1$ & 1 & 0.9 & 4.5 & 10 & $14 \cdot 1$ & $45 \cdot 4$ & 9 & $11 \cdot 8$ & $40 \cdot 9$ & 22 & $7 \cdot 3$ \\
\hline $\begin{array}{l}\text { Low access - Low \% } \\
\text { healthy }\end{array}$ & 4 & 8.9 & $6 \cdot 8$ & 14 & $12 \cdot 8$ & $23 \cdot 7$ & 15 & $21 \cdot 1$ & $25 \cdot 4$ & 26 & $34 \cdot 2$ & $44 \cdot 1$ & 59 & $19 \cdot 6$ \\
\hline $\begin{array}{l}\text { Moderate access - Low \% } \\
\text { healthy }\end{array}$ & 2 & 4.4 & $2 \cdot 0$ & 37 & 33.9 & 37.4 & 30 & $42 \cdot 3$ & $30 \cdot 3$ & 30 & 39.5 & $30 \cdot 3$ & 99 & 32.9 \\
\hline $\begin{array}{l}\text { High access - Low \% } \\
\text { healthy }\end{array}$ & 22 & $48 \cdot 9$ & 48.9 & 17 & $15 \cdot 6$ & $37 \cdot 8$ & 4 & $5 \cdot 6$ & 8.9 & 2 & $2 \cdot 6$ & 4.4 & 45 & 14.9 \\
\hline \multirow{2}{*}{$\begin{array}{l}\text { High access - Moderate \% } \\
\text { healthy }\end{array}$} & 15 & $33 \cdot 3$ & $21 \cdot 7$ & 40 & $36 \cdot 7$ & $58 \cdot 0$ & 9 & $12 \cdot 7$ & $13 \cdot 0$ & 5 & $6 \cdot 6$ & $7 \cdot 2$ & 69 & 22.9 \\
\hline & 45 & 100.00 & 14.9 & 109 & $100 \cdot 0$ & $36 \cdot 2$ & 71 & $100 \cdot 0$ & $23 \cdot 6$ & 76 & $100 \cdot 0$ & $25 \cdot 2$ & 301 & $100 \cdot 0$ \\
\hline Zero food retail & 0 & 0.0 & 0.00 & 0 & 0.0 & 0.00 & 2 & $2 \cdot 8$ & $50 \cdot 0$ & 2 & $2 \cdot 6$ & $50 \cdot 0$ & 4 & 1.3 \\
\hline $\begin{array}{l}\text { Low access - High \% } \\
\text { healthy }\end{array}$ & 2 & 4.4 & 10.5 & 1 & 0.9 & $5 \cdot 3$ & 11 & $15 \cdot 5$ & 57.9 & 5 & $6 \cdot 6$ & $26 \cdot 3$ & 19 & $6 \cdot 3$ \\
\hline $\begin{array}{l}\text { Low access - Low \% } \\
\text { healthy }\end{array}$ & 2 & 4.4 & $4 \cdot 3$ & 13 & 11.9 & $28 \cdot 3$ & 12 & $16 \cdot 9$ & $26 \cdot 1$ & 19 & $25 \cdot 0$ & $41 \cdot 3$ & 46 & $15 \cdot 3$ \\
\hline $\begin{array}{l}\text { Moderate access - Low \% } \\
\text { healthy }\end{array}$ & 4 & 8.9 & $4 \cdot 0$ & 30 & $27 \cdot 5$ & $29 \cdot 7$ & 29 & $40 \cdot 9$ & $28 \cdot 7$ & 38 & $50 \cdot 0$ & $37 \cdot 6$ & 101 & 33.5 \\
\hline $\begin{array}{l}\text { High access - Low \% } \\
\text { healthy }\end{array}$ & 17 & $37 \cdot 8$ & 39.5 & 18 & $16 \cdot 5$ & 41.9 & 5 & $7 \cdot 0$ & $11 \cdot 6$ & 3 & $4 \cdot 0$ & $7 \cdot 0$ & 43 & $14 \cdot 3$ \\
\hline $\begin{array}{l}\text { High access - Moderate \% } \\
\text { healthy }\end{array}$ & 20 & $44 \cdot 4$ & $22 \cdot 7$ & 47 & $43 \cdot 1$ & 53.4 & 12 & $16 \cdot 9$ & $13 \cdot 6$ & 9 & $11 \cdot 8$ & $10 \cdot 2$ & 88 & 29.2 \\
\hline Year: 2016 & 45 & $100 \cdot 0$ & 14.9 & 109 & $100 \cdot 0$ & $36 \cdot 2$ & 71 & $100 \cdot 0$ & 23.6 & 76 & $100 \cdot 0$ & $25 \cdot 2$ & 301 & $100 \cdot 0$ \\
\hline Zero food retail & 0 & 0.0 & 0.00 & 0 & 0.0 & 0.0 & 3 & $4 \cdot 2$ & $75 \cdot 0$ & 1 & $1 \cdot 3$ & $25 \cdot 00$ & 4 & 1.3 \\
\hline
\end{tabular}


Food retail environment typologies

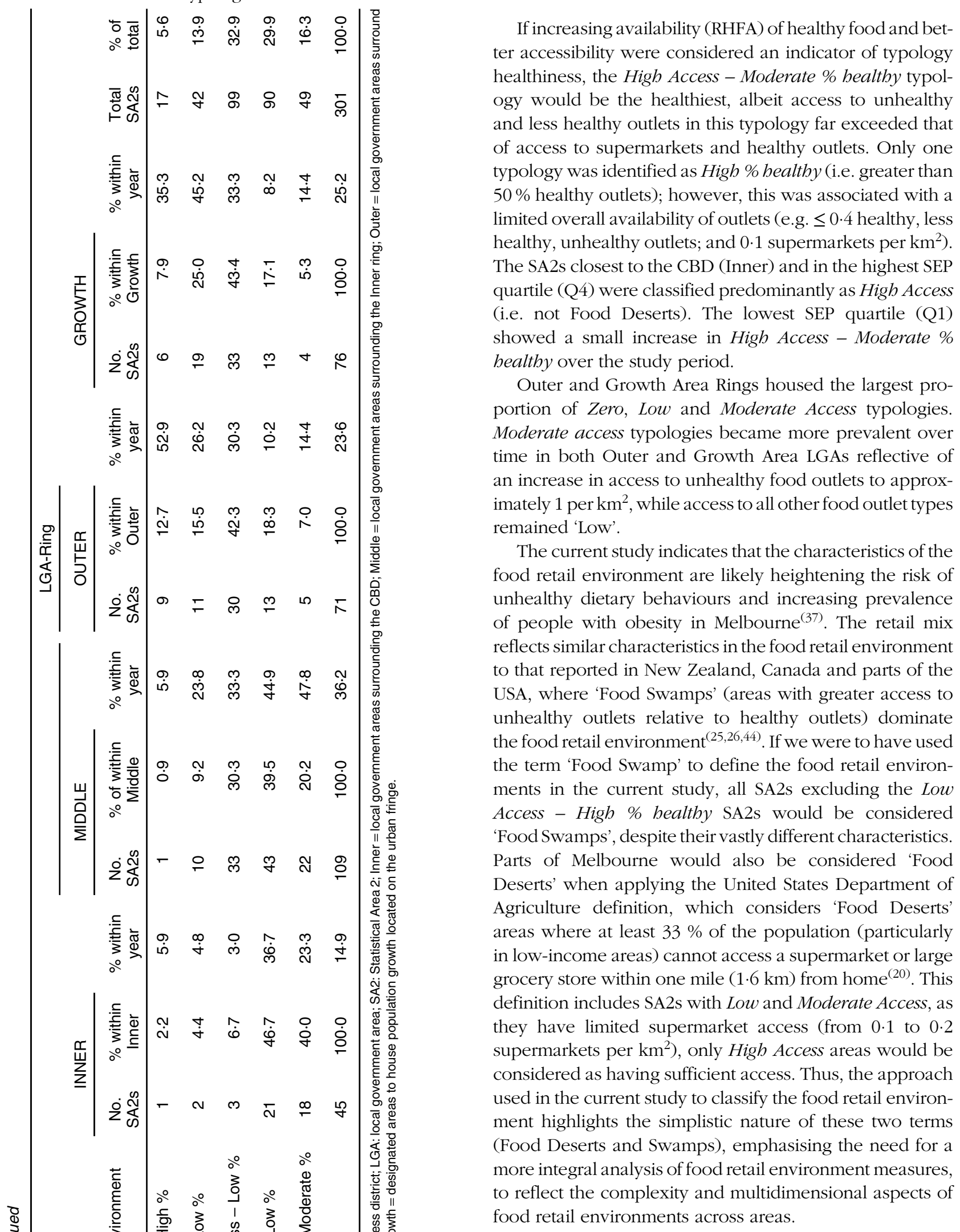

Health implications - food retail environment research

Evidence suggests that both having poor access to healthy food outlets and high access to unhealthy outlets 

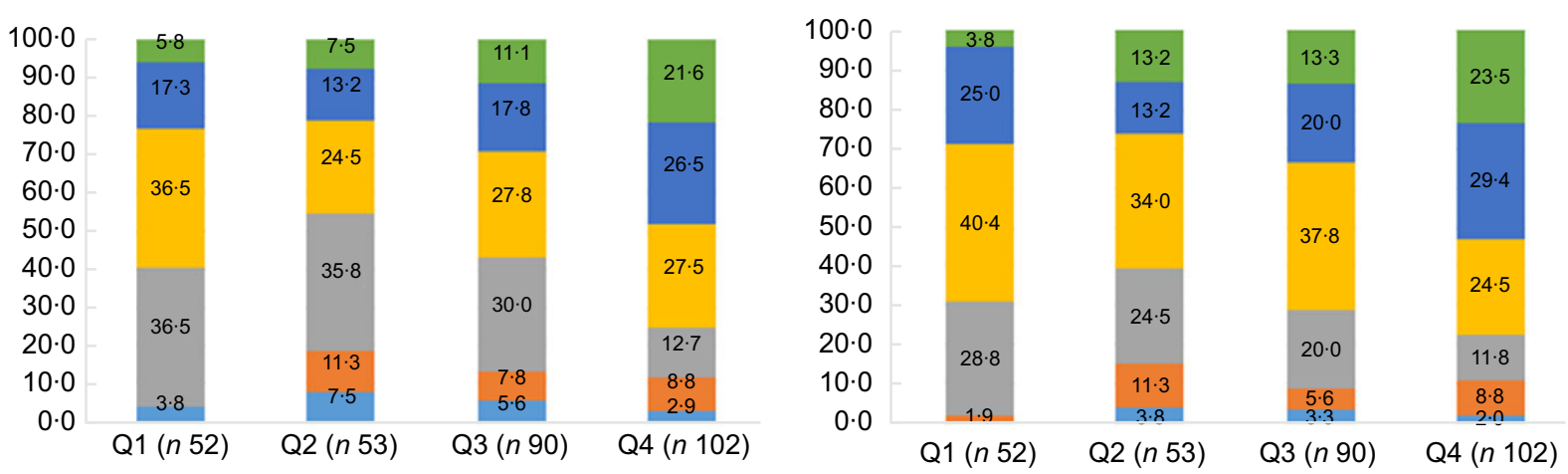

2014

2016
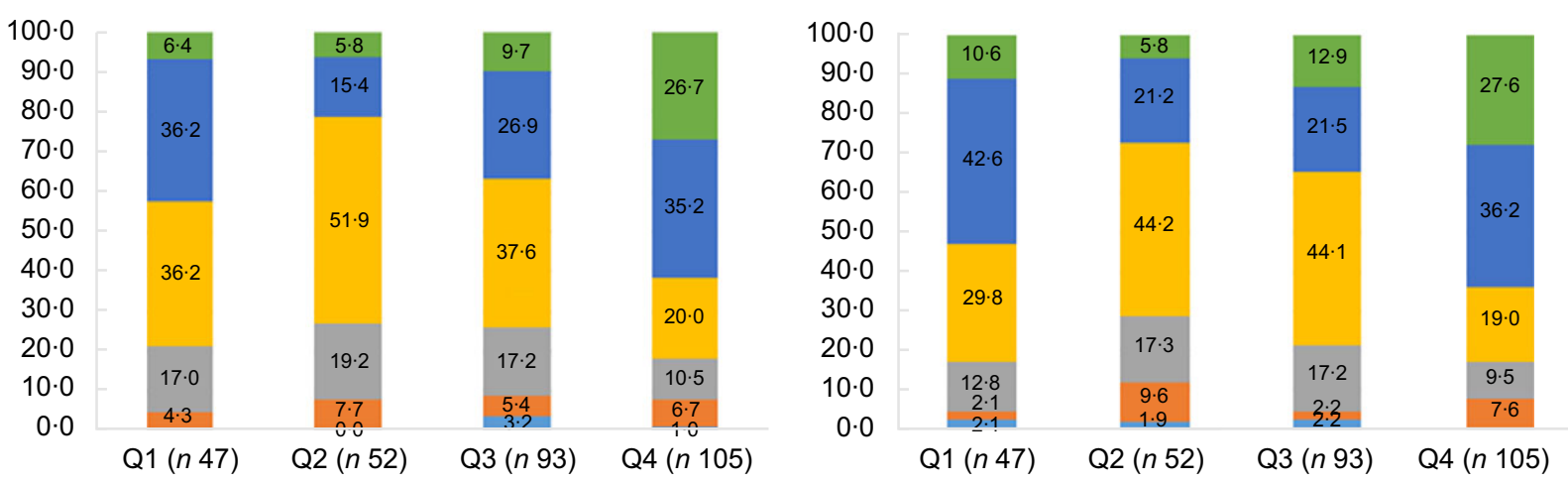

Fig. 1 Food retail environment typology distribution by area-level socioeconomic position quartiles within years. SEIFA-IRSAD: Socio-Economic Index for Areas, Index of Relative Socio-Economic Advantage and Disadvantage (Q1 = low socioeconomic position, Q4 = high socioeconomic position). $\sqsubset$, High access - moderate \% healthy; $₫$, High access - low \% healthy $\square$, Moderate access - low \% healthy $\sqsubset$, Low access - low \% healthy $\sqsubset$, Low access - high \% healthy $\sqsubset$, Zero food retail

relative to healthy outlets are associated with unhealthy weight $^{(17,37,45,46)}$. For example, an Australian study set in Adelaide found that one sd increase in the ratio of unhealthy to healthy food outlets within $1 \mathrm{~km}$ of participant's home address was associated with an $11 \%$ higher risk of participants having abdominal obesity ${ }^{(47)}$. Another study among adults ( $\geq 45$ years) in Sydney (Australia) also found significantly higher BMIs where unhealthy outlets accounted for $\geq 25 \%$ of all food outlets within a 1.6 and $3.2 \mathrm{~km}$ buffer from home ${ }^{(37)}$. Another study in Perth (Australia) found that with each additional healthy food outlet within $800 \mathrm{~m}$ of home, there was a $20 \%$ decrease in the risk of a child being overweight or obese after controlling for SEP, physical activity, sedentary behaviour, takeaway consumption, age and the presence of unhealthy outlets ${ }^{(46)}$. Given the evidence presented in the current study, findings suggest the characteristics of food retail environment in Melbourne are likely increasing the risk of unhealthy diet and weight ${ }^{(37)}$.

\section{Food retail environment disparities}

These findings highlight the inequities that exist within the food retail environment, with communities living in areas of lower SEP and further from metropolitan centres exposed to unhealthier food retail environments ${ }^{(11,15,19)}$. Several studies have found food retail environment disparities and negative health outcomes among lower SEP populations ${ }^{(48,49)}$. Evidence suggesting healthier food retail environments (i.e. areas with greater access to healthy food outlets) within $800 \mathrm{~m}$ and $1 \mathrm{~km}$ of home are supportive of a healthy BMI in areas of high disadvantage, but not so for those in areas of less disadvantage ${ }^{(48)}$. Similarly, in Melbourne, women without high school degrees or above living in low SEP areas had a higher BMI, partially explained by lower access to supermarkets, the coastline and sports facilities, when compared with women with the same education level in high SEP $\operatorname{areas}^{(50)}$

Food retail environment disparities have also been reported across Melbourne with people residing in Established Areas (urban areas not experiencing significant development and population growth) having significantly lower BMI and greater proximity and access (density) to supermarkets (within $800 \mathrm{~m}, 1.6 \mathrm{~km}$ and $2 \mathrm{~km}$ and $3 \mathrm{~km}$ ) and fast-food (within $800 \mathrm{~m}, 1 \mathrm{~km}, 1.6 \mathrm{~km}, 2 \mathrm{~km}$ and 3 $\mathrm{km}$ ) when compared with people in Growth Areas (i.e. new housing development areas $)^{(48,51)}$. Unexpectedly, further analysis of the data indicated fast-food density was positively associated with BMI in more established areas of Melbourne (within $800 \mathrm{~m}$ and $1000 \mathrm{~m}$ buffers), but 
negatively associated in Growth Areas (within $800 \mathrm{~m}$ and $1600 \mathrm{~m}$ buffers); after adjustment for a number of factors, including supermarket access, age, gender, measures of SEP and food and beverage consumption ${ }^{(51)}$.

It has been postulated in earlier research that the relationship between the food retail environment and obesity or dietary behaviours across areas, based on location and SEP, is driven by having greater access to healthier food outlets (e.g. supermarkets), which may play a protective role for $\mathrm{BMI}^{(15)}$. This is exemplified in the USA, where individuals with limited access to public transport and who did not own a vehicle appeared more vulnerable to the negative health impacts of living in areas where access to unhealthy food was disproportionately higher compared with healthy food, even after controlling for measures of SEP, recreation/fitness facilities and food deserts (absence or presence of supermarkets) ${ }^{(25)}$. In these instances, the physical environment in lower density areas (e.g. Growth Areas) where heavy car dependency, poor public transport, lower housing density and higher relative unhealthy food outlet accessibility is evident, we can expect an increased risk of unhealthy weight independent of $\operatorname{SEP}^{(25,51)}$

\section{Strengths}

Our approach to examining the food retail environment extends previous methods to identify new typologies, and our census of food outlets in 301 geographic areas gives a more detailed perspective of the food retail environment over time than has previously been reported. Results highlight the limitations of considering the food retail environment using only absolute measures of a single food outlet type, or use of terms such as Food Swamp and Food Desert, which by definition are simplistic. For example, despite extensive differences across measures of accessibility when considering only RHFA almost the entirety of Melbourne would be classified as a Food Swamp. However, when considering accessibility to healthy food outlets and supermarkets, a large proportion (all bar typologies that identify as High Access SA2s) would also be identified as a food desert. Using a combination of a data-driven and evidence-based approaches, we highlight the complexity of the food retail environment that exists across areas. The inclusion of supermarkets, which account for the bulk of food purchases in Australia (68\% of purchases in Australia in 2019) ${ }^{(33)}$, and healthy and unhealthy food retailers, which are the most influential food outlet types on purchasing and dietary behaviours, are strengths of the study ${ }^{(52)}$. The current study also included the often overlooked food outlets that cannot be clearly categorised as healthy or unhealthy, termed 'less healthy' food outlets, further strengthening results ${ }^{(11)}$. By measuring accessibility with density of food outlets within a predefined area unit (e.g. postcode, suburb), we proposed a method that can be applied at scale in public health settings $(15,17)$

\section{Weaknesses}

The food retail environment data set was extracted from hard copy business listings in the Yellow and White Pages, ground truthing was performed in 2019 on a sample of outlets and was limited by its retrospective nature ${ }^{(11)}$. Therefore, caution should be taken when assuming all food outlets are represented, as some outlets (e.g. those without a fixed-line telephone service or business listing) may have been overlooked. Supermarkets are often considered a the major source of fruit and vegetables within the food retail environment ${ }^{(22)}$ and are commonly used as a proxy for healthy food retail outlet availability ${ }^{(15)}$. However, they are also a large retailer of unhealthy food products ${ }^{(53)}$ and have a tendency to promote unhealthy food products heavily instore ${ }^{(54,55)}$. Following the Australian food outlets classification tool (range -10 to +10 ), supermarkets (as well as salad, sushi and sandwich outlets) received a rating of +5 , to reflect their contribution in retailing unhealthy as well as healthy food. Accessibility measures represent the average travel distance within each SA2 to access a food outlet, under the strong assumption that food outlets are spread evenly across the entire SA2 as is the population, which may not be a valid assumption. Additionally, evidence-based thresholds used to collapse clusters into typologies were drawn from earlier studies set in different countries and contexts and may be different in relation to food offered, behaviours and health outcomes in metropolitan Melbourne, Australia. It is acknowledged that over the study period some change to SA2 boundaries may have occurred. However, between 2011 and 2016, approximately $95 \%$ of SA2 boundaries remain effectively unchanged in Australia ${ }^{(34)}$. Nevertheless, for comparability, we used the year 2016 SA2 boundaries throughout. Finally, consistent with previous food retail environment studies, the SA2 'Melbourne' (i.e. the CBD) was excluded due to the fact that food outlets in this area mainly service visitors ${ }^{(36)}$.

\section{Recommendations/implications for practice}

The evidence to date suggests manipulating the food retail environment to support healthy food choices presents a potentially powerful opportunity to reduce the prevalence of obesity at the population level ${ }^{(3,25)}$. We present a key element for a comprehensive surveillance system which could provide evidence for planners, policy makers and interventionists, seeking to improve health through changing food retail environments. Implemented as part of a routine monitoring system, it would provide insight into drivers, trends and disparities in access to food resources, with particular emphasis on areas of low SEP and areas experiencing rapid population growth and expansion ${ }^{(11,25,56)}$. It is proposed that census measures of the entire food retail environment become the gold standard for future research, alongside measures guided by data-driven techniques that allow for identification of a broad range of food retail environment typologies. Additionally, it would be ideal for data to be provided by the relevant authority that regulates food 
retail (i.e. local governments) as these data are likely to have a higher level of accuracy ${ }^{(57)}$. These techniques are of international relevance for countries seeking to monitor, examine and identify emerging food retail environment trends and disparities alongside relationships with public health outcomes in greater detail. The evidence produced provides a source of data that could be linked to population health statistics to understand the relationships and trends over time, building the evidence base to support decision makers in favour of population health when challenged by the commercial interests of 'big food' ${ }^{\text {(1) }}$. Further research using typologies and both child and adult BMI and dietary behaviours alongside other factors that may also influence access to food retail (e.g. income, employment and car ownership) ${ }^{(58,59)}$ are required to examine the impact of different food retail environments on populations according to socio-economic and geographic strata.

\section{Conclusion}

We identified six food retail environment typologies representing relative healthy food availability and accessibility to the full spectrum of food outlets in Melbourne. All typologies were inherently unhealthy and pose potential increased risks to public health. Disparities across food retail environments were evident across areas of differing SEP and geographic locations and evolved over the eight-year study period. Communities living in low SEP areas and further from the CBD had largely low access to food outlets, and only a small proportion of these outlets were healthy. Whilst those living in areas of higher SEP and/or closer to the CBD were more likely to have high access to food outlets in general, and a marginally higher percentage of healthy outlets. This research provides new methods to understand the food retail environment and supports the need for food retail environment monitoring for the purposes of future research, strategic planning and enforcement of regulatory approaches to improve public health.

\section{Acknowledgements}

Acknowledgements: The current study was partially supported by a VicHealth Innovation Grant (IR27123) as part of a wider and related research project although separate from the current study. Needham, Allender and Orellana are researchers with the National Health and Medical Research Council (NHMRC) funded Centre of Research Excellence in Food Retail Environments for Health (REFRESH) (APP1152968). Financial support: No financial support was provided for the current study. Conflicts of interest: No conflicts of interest declared. Authorship: The lead author (C.N.) developed the research questions; collected and prepared data for analysis; undertook analysis of the data and interpreted results and wrote the final manuscript incorporating feedback from all authors. L.O. assisted with data preparation and analysis and assisted with interpretation of the results. L.O., C.S. and S.A. contributed to the refinement of the research idea/question; provided intellectual guidance on the preparation of results, recommendations and key findings; reviewed and provided significant feedback on the manuscript and approved the final manuscript. Ethics of human subject participation: The current study was conducted according to the guidelines laid down in the Declaration of Helsinki and an exemption for Ethics Review was granted for research undertaken by the Deakin University Human Research Ethics committee (reference number 2018-310) on 19 December 2018. The exemption was sought for two reasons accorded to the Australian National Statement on Ethical Conduct in Human Research: (1) Food environment data collected is publicly available and information not relating to humans and (2) The Victorian Population Health Survey data contain de-identified information, and methods and questionnaire content had previously received ethics approval by the Victorian Government, Department of Health/and Human Services' Human Research Ethics Committee.

\section{Supplementary material}

For supplementary material/s referred to in this article, please visit https://doi.org/10.1017/S136898002200009X

\section{References}

1. Swinburn BA, Kraak VI, Allender S et al. (2019) The global syndemic of obesity, undernutrition, and climate change: the Lancet commission report. Lancet 393, 791-846.

2. NCD RisC (2017) Worldwide trends in body-mass index, underweight, overweight, and obesity from 1975 to 2016: a pooled analysis of 2416 population-based measurement studies in 128.9 million children, adolescents, and adults. Lancet 390, 2627-2642.

3. Swinburn BA, Sacks G, Hall KD et al. (2011) The global obesity pandemic: shaped by global drivers and local environments. Lancet 378, 804-814.

4. Hawkes C, Harris H, \& Gillespie S (2017) Changing Diets: Urbanization and the Nutrition Transition. 2017 Global Food Policy Report. Washington, DC: International Food Policy Research Institute (IFPRI).

5. Bleich S, Cutler D, Murray C et al. (2008) Why is the developed world obese? Ann Rev Public Health 29, 273-295.

6. Scarborough P, Burg MR, Foster C et al. (2011) Increased energy intake entirely accounts for increase in body weight in women but not in men in the UK between 1986 and 2000. Br J Nutr 105, 1399-1404.

7. FAO (2001) Food Balance Sheets: A Handbook. Rome, Italy: United Nations.

8. Lucan SC, Maroko AR, Jin A et al. (2020) Change in an urban food environment within a single year: considerations for 
food-environment research and community health. Prev Med Rep 19, 101102.

9. Pérez-Ferrer C, Auchincloss AH, Barrientos-Gutierrez T et al. (2020) Longitudinal changes in the retail food environment in Mexico and their association with diabetes. Health Place $\mathbf{6 6}$, 102461.

10. Burgoine T, Lake AA, Stamp E et al. (2009) Changing foodscapes 1980-2000, using the ASH30 Study. Appetite 53, 157-165.

11. Needham C, Orellana L, Allender S et al. (2020) Food retail environments in greater Melbourne 2008-2016: longitudinal analysis of intra-city variation in density and healthiness of food outlets. Int J Environ Res Public Health 17, 1321.

12. Cohen N, Chrobok M \& Caruso O (2020) Google-truthing to assess hot spots of food retail change: a repeat cross-sectional Street View of food environments in the Bronx, New York. Health Place 62, 102291.

13. Maguire ER, Burgoine T \& Monsivais P (2015) Area deprivation and the food environment over time: a repeated cross-sectional study on takeaway outlet density and supermarket presence in Norfolk, UK, 1990-2008. Health Place 33, 142-147.

14. Swinburn B, Vandevijvere S, Kraak V et al. (2013) Monitoring and benchmarking government policies and actions to improve the healthiness of food environments: a proposed Government Healthy Food Environment Policy Index. Obes Rev 14, 24-37.

15. Needham C, Sacks G, Orellana L et al. (2020) A systematic review of the Australian food retail environment: characteristics, variation by geographic area, socioeconomic position and associations with diet and obesity. Obes Rev 21, e12941. doi: 10.1111/obr.12941.

16. Stevenson AC, Brazeau A-S, Dasgupta K et al. (2019) Neighbourhood retail food outlet access, diet and body mass index in Canada: a systematic review. Health Promot Chronic Dis Prev Canada: Res Policy Pract 39, 261-280.

17. Gamba R, Schuchter J, Rutt C et al. (2015) Measuring the food environment and its effects on obesity in the United States: a systematic review of methods and results. J Community Health 40, 464-475.

18. Cummins S \& Macintyre S (1999) The location of food stores in urban areas a case study in Glasgow. Br Food J 101, 545-553.

19. Beaulac J, Kristjansson E, Cummins S (2009) A systematic review of food deserts, 1966-2007. Prev Chronic Dis 6, A105.

20. CED (2016) Healthy Food Financing Initiative FY 2016. Seattle: Office of Community Services.

21. Wilkins E, Morris M, Radley D et al. (2019) Methods of measuring associations between the Retail Food Environment and weight status: importance of classifications and metrics. SSM - Popul Health 8, 100404.

22. Mason KE, Bentley RJ \& Kavanagh AM (2012) Fruit and vegetable purchasing and the relative density of healthy and unhealthy food stores: evidence from an Australian multilevel study. J Epidemiol Commun Health 67, 231-236.

23. Meyer KA, Boone-Heinonen J, Duffey KJ et al. (2015) Combined measure of neighborhood food and physical activity environments and weight-related outcomes: the CARDIA study. Health Place 33, 9-18.

24. Hui L, Law J \& Quick M (2015) Identifying food deserts and swamps based on relative healthy food access: a spatiotemporal Bayesian approach. Int J Health Geographics 14, $1-11$

25. Cooksey-Stowers K, Schwartz MB \& Brownell KD (2017) Food swamps predict obesity rates better than food deserts in the United States. Int J Environ Res Public Health 14, 1366.

26. Luan H, Law J \& Quick M (2015) Identifying food deserts and swamps based on relative healthy food access: a SpatioTemporal Bayesian approach. Int J Health Geographics 14, 37.
27. O'Dwyer LA \& Coveney J (2006) Scoping supermarket availability and accessibility by socio-economic status in Adelaide. Health Promot J Australia 17, 240-6.

28. Gordon-Larsen P (2014) Food availability/convenience and obesity. Adv Nutr 5, 809-17.

29. Hawkes C (2008) Dietary implications of supermarket development: a global perspective. Dev Policy Rev 26, 657-692.

30. Moayyed H, Kelly B, Feng X et al. (2017) Evaluation of a 'healthiness' rating system for food outlet types in Australian residential communities. Nutr Diet: J Dietitians Assoc Australia 74, 29-35.

31. DELWP Victoria in Future 2019 (2019) Population Projections 2016 to 2056. Department of Land Water and Planning. Melbourne: Victorian State Government.

32. Sensis Data (2019) Frequently Asked Questions. https:// www.sensis.com.au/help/faqs-yellow-pages-print (accessed August 2019).

33. Crothers L (2019) Australia Retail Foods: Retail Food Sector Report 2019. USDA Foreign Agricultural Service: Global Agricultural Information Network. https://apps.fas.usda. gov/newgainapi/api/report/downloadreportbyfilename? filename=Retail\%20Foods_Canberra_Australia_6-27-2019.pdf (accessed February 2020).

34. ABS (2016) 1270.0.55.001 - Australian Statistical Geography Standard (ADGS): Volume 1 - Main Structure and Greater Capital City Statistical Areas, July 2016: Australian Federal Government. https://www.abs.gov.au/ausstats/abs@.nsf/ Lookup/by\%20Subject/1270.0.55.001 July\%202016 Main \%20Features Statistical\%20Area\%20Level\%202 \%20(SA2) $\sim 10014$ (accessed January 2020).

35. ABS (2018) Estimated Resident Population (ERP) and Components by LGA (ASGS 2018) 2001 to 2018. Canberra: Commonwealth of Australia.

36. Thornton LE, Lamb KE \& Ball K (2016) Fast food restaurant locations according to socioeconomic disadvantage, urbanregional locality, and schools within Victoria, Australia. SSM - Popul Health 2, 1-9.

37. Feng X, Astell-Burt T, Badland H et al. (2018) Modest ratios of fast food outlets to supermarkets and green grocers are associated with higher body mass index: longitudinal analysis of a sample of 15229 Australians aged 45 years and older in the Australian National Liveability Study. Health Place 49, 101-110.

38. Mackenbach JD, Charreire H, Glonti K et al. (2019) Exploring the relation of spatial access to fast food outlets with body weight: a mediation analysis. Environ Behav 51, 401-430.

39. Hastie T, Tibshirani R \& Friedman J (2009) The Elements of Statistical Learning: Data Mining, Inference, and Prediction. New York: Springer.

40. DSE (2005) A Plan for Melbourne's Growth Areas. Melbourne: State Government of Victoria.

41. ABS (2011) Census of Population and Housing: SocioEconomic Indexes for Areas (SEIFA). Canberra: Commonwealth of Australia.

42. ABS (2016) Census of Population and Housing: SocioEconomic Index for Areas (SEIFA). Canberra: Commonwealth of Australia.

43. ABS (2016) 2033.0.55.001 Technical Paper Socio-Economic Indexes for Areas (SEIFA). Canberra: Commonwealth of Australia.

44. Vandevijvere SM, Mackay S, D'Souza E et al. (2018) How Healthy Are New Zealand Food Environements? A Comprehensive Assessment 2014-2017. New Zealand: INFORMAS.

45. Giskes K, van Lenthe F, Avendano-Pabon M et al. (2011) A systematic review of environmental factors and obesogenic dietary intakes among adults: are we getting closer to understanding obesogenic environments? Obes Rev 12, e95-e106.

46. Miller LJ, Joyce S, Carter S et al. (2014) Associations between childhood obesity and the availability of food outlets in the 
local environment: a retrospective cross-sectional study. $\mathrm{Am}$ J Health Promot 28, e137-e145.

47. Paquet C, Coffee NT, Haren MT et al. (2014) Food environment, walkability, and public open spaces are associated with incident development of cardio-metabolic risk factors in a biomedical cohort. Health Place 28, 173-176.

48. Murphy M, Koohsari MJ, Badland H et al. (2017) Supermarket access, transport mode and BMI: the potential for urban design and planning policy across socio-economic areas. Public Health Nutr 20, 3304-3315.

49. Thornton LE, Bentley RJ \& Kavanagh AM (2011) Individual and area-level socioeconomic associations with fast food purchasing. J Epidemiol Community Health 65, 873-880.

50. Abbott G, Backholer K, Peeters A et al. (2014) Explaining educational disparities in adiposity: the role of neighborhood environments. Obesity 22, 2413-2419.

51. Murphy M, Badland H, Jordan H et al. (2018) Local food environments, Suburban development, and BMI: a mixed methods study. Int J Environ Res Public Health 15, 1392.

52. Gordon-Larsen P (2014) Food availability/convenience and obesity. Adv Nutr 5, 809-17.
53. Cameron AJ (2018) The shelf space and strategic placement of healthy and discretionary foods in urban, urban-fringe and rural/non-metropolitan Australian supermarkets. Public Health Nutr 21, 593-600.

54. Riesenberg D, Backholer K, Zorbas C et al. (2019) Price promotions by food category and product healthiness in an Australian Supermarket Chain, 2017-2018. Am J Public Health 109, 1434-1439.

55. Zorbas C, Gilham B, Boelsen-Robinson T et al. (2019) The frequency and magnitude of price-promoted beverages available for sale in Australian supermarkets. Australian NZ J Public Health 43, 346-351.

56. Lopez R (2004) Urban sprawl and risk for being overweight or obese. Am J Public Health 94, 1574-1579.

57. Lake AA, Burgoine T, Greenhalgh F et al. (2010) The foodscape: classification and field validation of secondary data sources. Health Place 16, 666-673.

58. Widener MJ (2018) Spatial access to food: retiring the food desert metaphor. Physiol Behav 193, 257-260.

59. Battersby J (2012) Beyond the food desert: finding ways to speak about urban food security in South Africa. Geografiska Annaler Series B: Human Geography 94, 141-159. 